\title{
THE UNITED NATIONS CONVENTION ON THE RIGHTS OF PERSONS WITH DISABILITIES AND ITS EFFECTS ON THE PROMOTION OF ELITE DISABILITY SPORT: A WORLDWIDE ANALYSIS
}

\begin{abstract}
JAIME PRIETO ${ }^{1}$
JUAN L. PARAMIO-SALCINES ${ }^{2}$

Abstract: Little attention has been focused on the analysis of the interrelation between disability and elite disability sport from the human rights perspective as the United Nations Convention on the Rights of Persons with Disabilities (UNCRPD) demands of those countries that ratified this global regulation. More than a decade since its promulgation in December 2006, the United Nations itself and a plethora of authors recognises that disability in general and disability sport by extension has not yet been seen as a human rights issue in many countries, principally in developing countries. This paper is divided into four main parts. First, academic literature in relation to disability, human rights policy and sport at elite level is explored. Second, it examines the active role of the International Paralympic Committee, regarded as a major advocate for the rights of the sport promotion of athletes with disabilities, to implement the Convention by the organisation of sports events for Paralympic athletes worldwide at all levels of the sport development continuum. Third, it explains the methods and data collection followed in the study and the following section presents results of the analysis. Finally, it draws an international scenario that might be valuable in informing academics, institutions and professionals to promote elite disability sport from the human rights perspective.
\end{abstract}

Keywords: United Nations’ Convention on the Rights of Persons with Disabilities; human rights; people with disabilities; disability sport; elite disability sport; International Paralympic Committee.

\section{INTRODUCTION}

It is commonly assumed that leisure and sport participation are fundamental parts in the daily lives of all people living in any country, including those people with disabilities $(\mathrm{PwD})^{3}$. Regarded as the world's largest minority group by the World Health Organization/World Bank in the first World report on disability (WHO and WB 2011), PwD represent over one billion people (about 15\% of the world's population) having

\footnotetext{
${ }^{1}$ Faculty of Education, Department of Languages, Arts and Physical Education, Universidad Complutense de Madrid, Spain (jaimeprietobermejo@gmail.com).

${ }^{2}$ Faculty of Teacher Training and Education. Departament of Physical Education, Sports and Human Movement, Universidad Autónoma de Madrid, Spain (juanluis.paramio@uam.es).

${ }^{3}$ Although how to use the term to define disabled people or people with disabilities has become the subject of intellectual and ideological controversy in the disability studies literature as part of the ongoing debate about societal-level perspectives for thinking about and researching into disability (the medical and social models). As part of this debate, there are some authors advocating the use of the term disabled (see Thomas and Smith 2009; Aitchison 2009; Darcy and Taylor 2009 for a broader discussion), while others advocating the use of the term people with disabilities, in this article, the authors will use people with disabilities (PwD) as the unifying terminology widely accepted by the predominant social model of disability.
} 
some form of disability (WHO 2013). This figure represents an emerging challenge for policy makers, academics, managers and other stakeholders involved in disability sport around the world as the percentage of this growing global segment of population will continue to increase in the coming five decades (Eurostat 2015; WHO and WB 2011).

Since the first half of the twenty century, the widespread consideration of access to leisure and sport for $\mathrm{PwD}$ from the human rights perspective in a plethora of countries (see Donnelly 2008; Roy 2007; Misener and Darcy 2014; Paramio-Salcines, Prieto and Llopis-Goig 2018; Veal 2015) has led to the promulgation of a substantial body of international declarations and legislations. Looking back in retrospect, the United Nations Declaration of Human Rights (1948) along with other documents have been influential on promoting human rights for many groups, though the rights of PwD, as Darcy and Taylor (2009) remark, were not specifically mentioned in this declaration. Thereafter, the United Nations Declaration on the Rights of Disabled Persons (1975) and especially the International Year of Disabled Persons (IYD) are valued as the genesis of the promotion of human rights for PwD. In the meantime, the 'Sport for All' movement, promoted officially by the European Council in 1966, has also contributed to promoting policies and programmes to facilitate equality of access and encourage participation not only for mass participation but also competitive sport for this 'priority group' in many countries over the last decades. However, the United Nations Convention on the Rights of Persons with Disabilities (hereafter UNCRPD), passed in December 2006, represents the first legally binding instrument that urges governments throughout the world to take proactive and responsive policies, including legislation, to ensure specifically the right of PwD "to participate on an equal basis with others in recreational, leisure and sporting activities" (article 30.5.c) (United Nations 2006; see also Darcy and Taylor 2009; Misener and Darcy 2014). In this paper, human rights are defined, following Keywood (2000: 131), as "rights to which people are entitled by virtue of being human.... and are universal, fundamental and absolute. [...] They are universal as they belong to all human everywhere, regardless of nationality, ethnic or racial origin, social background, impairments and so on. They are fundamental as human rights can be denied or violated but a human being's entitlement to them cannot be removed". As part of the general obligations of those signatory countries of the UNCRPD, with 172 countries $^{4}$ in October 2017 (United Nations, 2016; European Disability Forum, 2017), governments are responsible for delivering elite disability sport ${ }^{5}$ (DePauw and Gavron 2005; Misener and Darcy 2014; Thomas and Smith 2009), as part of the sport development continuum alongside the 'Sport for All' movement (Hylton, Bramham, Jackson and Nesti 2001). Similarly, organisations such as the World Health Organization (WHO 2013; WHO and WB 2011), the World Leisure Organization (Sotiriadou and Wicker 2014), the European Commission (European

\footnotetext{
${ }^{4}$ As of October 2017, it has 160 signatories and 175 parties, which includes 172 countries and the European Union (EU) (which ratified it on 23 December 2010 to the extent responsibilities of the countries were transferred to the European Union). At the time of writing, 27 of the 28 member States of the EU have ratified, in particular Spain ratified the UNCRPD on December 2007, being Ireland the only EU member State that has not yet ratified (European Disability Forum 2017).

${ }^{5}$ Following Thomas and Smith (2009: 3), the term disability sport will be used 'to describe those sports activities that have developed for the specific involvement of disabled people and which provide opportunities for disabled people to compete with or against other disabled people' from grassroots to elite levels as we argue in this article.
} 
Disability Forum 2017) or the International Paralympic Committee (IPC) (IPC 2015) clearly coincide with the UNCRPD and other declarations to approach disability sport from the human rights perspective.

The UNCRPD adopts a broad categorisation of disability that initially "includes those who have long-term physical, mental, intellectual or sensory impairments which, in interaction with various barriers, may hinder their full and effective participation in society on an equal basis with others" (United Nations 2006; Article 1: Purpose). Misener and Darcy (2014) argued that this categorisation does not cover the whole picture of disability. Based on the criteria followed by Ontario Human Rights Commission to define disability, both authors underline the need to "expand upon these basic four impairment types to include, for example, learning, hearing or vision disabilities, epilepsy, drug and alcohol dependencies, environmental sensitivities, as well as others" (p. 2). Since the 1990s a large number of Western countries such as the US (Hums, Schmidt, Novak and Wolff 2016), Australia (Darcy and Taylor 2009; Darcy, Taylor and Green 2016; Sotiriadou and Wicker 2014) and European countries such as the UK (EHRC 2017), Germany and Spain (Paramio-Salcines, Kitchin and Downs 2018) have passed, building on the UNCRPD, extensive policies and legislative developments of disability rights, anti-discrimination and accessibility to sport and active leisure.

It is more than a decade since the UNCRPD was passed, and the key question remains as to how effective this global treaty has been in guaranteeing the rights of this growing segment of population in relation to sport participation. When evaluating the impact of this global treaty for the lives and rights of PwD, the reality is far from ideal, as the United Nations itself (United Nations 2016) and more recently other organisations such as the Equality and Human Rights Commission at the UK (EHRC 2017) along with different authors (Darcy and Taylor 2009; Darcy et al. 2016; Donnelly 2008; Roy 2007; Singleton and Darcy 2013; Thomas and Smith 2009; Veal 2015) coincide in noting that disability in general and disability sport by extension has not yet been seen as a human rights issue not only in Western countries, but principally in developing countries, which is specifically examined in this article. Veal (2015: 250) argues that despite the fact that "the idea of human rights permeates many aspects of national and international life, it has not permeated the field of leisure studies to any great extent'. Concern that extends to the sport field as Donnelly (2008: 381) notes, saying that "despite the human rights achievements in sport...human rights are also continually and routinely violated in ways that are directly or indirectly related to sport” (see also Misener and Darcy 2014). To compare evidence as a whole before and after the establishment of the UNCRPD, it is therefore instructive to take account of the United Nations Secretary-General Ban Kimoon's statement in December 2016, which clearly stated that "in the past decade, we have seen much progress. But, persons with disabilities continue to face grave disadvantages" (United Nations 2016). To address this situation, Ban Ki-moon urged "the international community to end discrimination, remove barriers and ensure equal participation for all persons with disabilities, who are still commonly denied fundamental rights, and are more likely to live in poverty" (United Nations 2016), where the inclusion and participation of PwD in sport environments at all levels are fundamental rights and not an exception. 
Despite the launching and implementation of a wide range of positive international and national policies and legislations, there is even today evidence that $\mathrm{PwD}$ around the world are at a disadvantage compared to non-disabled people in critical areas such as employment and unemployment, annual income, health, and in our case, sporting participation, from the lowest to the highest level of achievement, in countries like the United States (Erickson, Lee and von Scharader 2014), the UK (Sport England 2016, 2017; EHRC 2017), Australia (Australian Sport Commission 2010; 2016) or Spain (Spanish Paralympic Committee 2016). Despite the fact that disability sport has developed rapidly in the last decades and PwD now take part in sport at all levels in many countries (Thomas and Smith 2009), differences between PwD and those without disabilities are even today quite significant (e.g. Paramio-Salcines, Prieto and LlopisGoig, 2018). Most of the above data comes predominantly from Western countries, while there are fewer studies in many other parts of the world, principally from developing countries. Unlike Western countries, many developing countries, as Shukshin (2005) claims, have not enacted comprehensive disability and accessibility legislation to promote the rights of PwD to equally of access to leisure and sport environments.

As part of the fundamental human rights agenda for our population group, governments have been also asked to take positive initiatives to promote elite disability sport as we argue in this article (De Jong, Vanreusel and Van Driel 2010; DePauw and Gavron 2005; Misener and Darcy 2014; Thomas and Smith 2009). To date, the analysis of the interrelation between disability and elite disability sport as well as the emergence and development of elite disability sport has only recently attracted the attention of leisure and sport management academics (e.g. Brittain 2016a; Brittain and Wolff 2015; De Jong et al. 2010; DePauw and Gavron 2005; Misener and Darcy 2014; Nicholson and Stewart 2013; Pitts and Shapiro 2017; Shapiro and Pitts 2014; Thomas and Smith 2009; Veal 2015). To analyse this phenomenon, national policy developments in the field of competitive and disabled-specific federated sports is a major area to be considered. To fulfil this aim, governments are urged to provide appropriate instruction, training and more resources for the organisation, development and participation of PwD in disability sport in general and elite disability sport in particular. Under those circumstances, national sports federations are playing a key role in assisting governments in the undertaking of the competences concerning to a particular sport with leisure, social and training purposes. With regard to elite disability sport, there is a complex network of global organisations such as the International Paralympic Committee (IPC) working in conjunction with national sports federations where there is a disability-specific section within the able-bodied federation structure itself, whilst other federations or entities are configured independently to the non-disabled sport. In addition to national sports federations, there exist other governmental and non-governmental entities that deal with issues related to the participation in sporting activities by PwD. The role of the aforementioned disabled-specific organisations is to encourage this group of population to participate at all levels of mainstream disability sport and elite sport competitions, including the Summer and Winter Olympic Games and international competitions for athletes with specific impairments (e.g. motor, visual, hearing or intellectual) (e.g. DePauw and Gavron 2005; Thomas and Smith 2009). Such has been the growing internalisation and competitiveness of disability sport at elite level that, for instance, the 
latest Paralympic Games held from 7 to 18 September 2016 in Rio was regarded as the largest Paralympic Games ever and the best Games in terms of athletic performance with 4,328 athletes (2,657 males and 1,671 females) participating in 22 sports, two more than in London 2012 (see https://www.paralympic.org/rio-2016).

Within this context, with the aim of analysing the international global picture of disability sport from a human rights perspective, it was hypothesised that the presence of the signatory countries of the UNCRPD in the different disabled-specific international federations and/or organisations for the various disabled sports would reflect, at least in the institutional-organisational level, their first commitment to manage, promote and develop the fundamental rights of PwD to participate in sport on an equal basis with others, in particular providing competition opportunities for their athletes in different sports and disability groups at the international level.

This paper is divided into four main parts. The first section begins with a review of how academic literature has covered the development of the body of knowledge in relation to disability, human rights policy and elite disability sport. The following section examines the active role and responsibilities of the International Paralympic Committee (IPC) to implement the UNCRPD by organising sports events for Paralympic athletes worldwide at all levels. The subsequent section explains the methods and data collection followed in the study and the section after presents results of the analysis. Finally, the paper draws an international scenario that might be valuable in informing academics, institutions and professionals to promote closer integration between disability sport at elite level from the human rights perspective. This article examines in much detail the potential differences in terms of geographical location and impairment-specific sports and states some limitations of the study.

\section{UNDERSTANDING DISABILITY, ELITE DISABILITY SPORT AND HUMAN RIGHTS POLICY}

As a logical point of departure, it is important to highlight disability and elite disability sport from the human rights perspective. To the former, the World Health Organization states that "disability is not only a public health issue, but also a human rights and development issue" (WHO 2013; WHO and WB 2011). As already mentioned, the UNCRPD clearly sets the tone about the rights of $\mathrm{PwD}$ at international level and incorporates disability and disability sport as a human rights issue. As part of the general obligations of those countries that ratified the UNCRPD, central governments must adopt legislation and other appropriate policies to provide people with different disabilities all the opportunities to enjoy sport at all levels, including elite disability sport (IPC 2015).

To start with, it is relevant to acknowledge the work of Shapiro and Pitts (2014) who after examining disability sport in sport management literature between 2002 to 2012 remark that research on disability sport, leisure and recreation is still an under research area in sport management. To further this argument, both authors state that out of 5,443 articles examined, only 89, less than 1 per cent were disability sport articles (see also Pitts and Shapiro 2017). In this regard, the World Leisure Journal was (and still is) one of the 
journals that has published more articles in this subject (Veal 2015). To date, most of the extant research on sport and leisure disability has focused upon the level of sport participation and the range of activities involving PwD (Patterson and Pegg 2009; Pitts and Shapiro 2017; Shapiro and Pitts 2014; Thomas and Smith 2009), and more recently on the analysis of another growing demographic group as old PwD (Sotiriadou and Wicker 2014). Shapiro and Pitts (2014: 663) found that 'nearly half (48\%) of all papers addressing disability sport focused on "participant sport”, followed by Paralympics (15.7\%)'. In addition, much of studies are mainly descriptive in nature and focused on highlighting the lower level of sport participation patterns of our population group compared to non-PwD and the main barriers that constrain the sporting participation of our target group. As mentioned previously, recent studies confirm that the levels and types of sport participation by PwD in different Western countries such as the US (Erickson et al. 2014), the UK (Brittain 2016a; Sport England 2016, 2017), Australia (Australian Sport Commission 2010, 2016) or Spain (Spanish Paralympic Committee 2016) have steadily increased but still lags significantly behind able-bodied participation. In England, for instance, the latest study undertaken by Sport England estimates that there are still significant differences between those with and without disabilities, with 'only 36 per cent of those with three or more impairments are active compared with 65 per cent of those without a disability' (Sport England 2017: 12). In Spain, although there is no official data on the level of sports participation of PwD (MECD 2016), the Spanish advocacy group CERMI (the Comite Español de Representantes de Personas con Discapacidad) (Spanish Committee of Representatives of People with Disabilities) argues that 'nearly one million people with disabilities (out of an overall figure of 3.8 million people with disabilities in the country) take part in sport, around 25 per cent of the overall number of people with disabilities' (Spanish Paralympic Committee 2016: 3; see also Paramio-Salcines, Prieto and Llopis-Goig 2018). As the UNCRPD recognises and different sport policies in many Western countries, increasing sport participation rates of PwD has been one of the key strategic objectives of any sport policy from macro level to micro level.

Similarly, past studies in the area of disability sport have also focused on analysing the number of interrelated (potential) political, physical, social and cultural barriers that might explain the lower levels of sport participation of PwD in Western countries (e.g. societal attitudes towards disability, effective policy-making for the implementation of universal accessibility to sports venues and events, inaccessible venues and services, disability sport provision at all levels or lack of disability-specific knowledge) (Hylton and Totten 2001, Misener and Darcy 2014; Radke and Doll-Tepper 2011; Thomas and Smith 2009). Misener and Darcy (2014: 3) argue that "much of the lower levels of participation are attributed to discriminatory management practices rather than a lack of desire to participate". Hylton and Totten (2001) goes further to suggest that discrimination against disability in sport can be observed at three levels: a) individual (micro); b) at institutional (meso); and c) societal level (macro). This structure serves to focus our analysis on the meso (understood by central and local governments and sport governing bodies) and societal level.

According to Shapiro and Pitts (2014) and Pitts and Shapiro (2017), the second area of interest, though limited, was the study of the Paralympics and Paralympic athletes; 
however, the analysis of the interrelation between disability and elite disability sport from a human rights perspective is still an under research area both for the leisure and sport management studies as previously stated. As Misener and Darcy (2014) argue, relatively little studies in disability sport have explored the implementation of policies for elite disability sport athletes from a human right perspective. Moreover, implementing effective policies to ensure that $\mathrm{PwD}$ have the same sporting opportunities still remains a managerial challenge in both Western countries and mainly in developing countries. Especially when considering that one of the reasons that might explain the resistance from upper level managers to the implementation of inclusive and accessible sporting environments comes from the underestimation of the significance of PwD as a customer group (Paramio-Salcines, Grady and Downs 2014).

Although those signatory countries of the UN Convention must promote sports opportunities in all levels of the sport development continuum, previous research has highlighted the lack of participation from developing countries in international disability sport events, especially in heavily indebted poor countries (Cottingham, Blais, Gearity, Bogle and Zapalac 2015). In particular, several factors may have influenced the lack participation of athletes from developing countries in international disability competitions (e.g. political factors, historical origins and regional growth of international governing bodies and their membership, location of the host city and associated travel costs, climate and geographic barriers, etc.) (Lauff 2011), hence hindering the potentialities of PwD from these countries to become Paralympic athletes (IPC 2011a, 2015). Following Aitchison (2009), Misener and Darcy (2014), Pitts and Shapiro (2017), Shapiro and Pitts (2014) and Veal (2015), one of the aims of this paper is to extent the focus of disability sport and elite disability sport from the human rights perspective.

\section{The role of the International Paralympic CommitTee (IPC) TO PROMOTE THE RIGHTS OF PWD AT THE SPORTING LEVEL}

As part of its mission statement in their Strategic Plan 2015 to 2018 and as the principle global governing body of the Paralympic movement, the IPC is a major advocate for the rights of the sport promotion of all athletes with disabilities (or para-athletes) worldwide (IPC 2015). Similarly to other organisations, the IPC aims to increase and improve sport opportunities and competitions for para-athletes from grassroots to elite levels (Chappelet 2014; Thomas and Smith 2009). As such, the IPC's most outstanding area of concern is the organisation of both the Summer and Winter Paralympic Games, regarded as the world's third biggest sporting event, which represent the peak moment of each four-year sports cycle for Paralympic athletes worldwide. To fulfil the above mission, all athletes participating in the Paralympic Games or other World and Regional Championships in 13 sports (including athletics and swimming) controlled by the IPC itself must be nationals of one of the countries recognised by this organisation and be represented by their National Paralympic Committees (NPC) (IPC 2011b, 2015). The NPCs are national entities representing para-athletes for each of the IPC member countries. The functioning of these national governing bodies is diverse and often agglutinates various national disability federations for different sports and specific impairment groups with other national sporting organisations for the disabled. The NPCs 
are responsible, among others, for the organisation of disabled-specific competitions on the local level around the country and for the supervision and coordination of their athletes’ participation in all IPC international competitions as mentioned earlier.

Apart from these responsibilities, the IPC cooperates with International Federations that act as the sole representative for para-athletes of a particular sport, either as part of the able-bodied International Federation (e.g., para-cycling is governed by the International Cycling Union (UCI)) or as an independent disabled international federation (e.g. International Wheelchair Basketball Federation), for a current total number of 17 International Federations (available for consultation on the IPC website). In particular, the IPC acts as the International Federation for nine sports (e.g. IPC Alpine Skiing, IPC Athletics, IPC Powerlifting), usually referred to as IPC sports. Furthermore, the IPC recognises various international organisations as the representative of a specific impairment group under the umbrella of the International Organisations of Sports for the Disabled (IOSDs). The IPC currently recognises four IOSDs: Cerebral Palsy International Sports and Recreation Association (CPISRA), International Blind Sports Federation (IBSA), International Sports Federation for Persons with an Intellectual Disability (INAS), and International Wheelchair and Amputee Sports Federation (IWAS). These organisations work in partnership with the IPC to provide specific expertise to promote sport for athletes with a specific impairment-related condition at all levels. As was argued, the presence of the UNCRPD signatory countries in the aforementioned organisations determines an important first institutional step for the fulfilment of opportunities provision for their athletes with disabilities to participate in international sporting competitions.

\section{ANALYSIS METHOD}

\section{Procedure}

To inform this relatively unexplored theme in the leisure and sport academic literature, a worldwide country situation analysis was conducted. In a first step of the analysis, the authors checked whether each of the currently 172 signatory countries of the UNCRPD had a National Paralympic Committee (NPC), as these entities act as the national disabled sport organisations recognised by the IPC enabling the participation of athletes from these countries in all the designated IPC competitions (International Federations recognised by the IPC and IPC sports). The list of the NPCs is available for consultation on the IPC website (https://www.paralympic.org/). Parallel to this data collection, additional information was included after reviewing the membership of the Convention signatory countries within the four International Organisations of Sports for the Disabled (IOSDs): Cerebral Palsy International Sports and Recreation Association (CPISRA), International Blind Sports Federation (IBSA), International Sports Federation for Persons with an Intellectual Disability (INAS), and International Wheelchair and Amputee Sports Federation (IWAS). Descriptive data (total numbers and percentages) of the Convention signatory countries' membership within the IPC and the IOSDs was calculated. As part of this comparative study and in order to draw the international map, data was grouped by geographical regions as explained in the following section. 


\section{Geographical coverage and level of development of the countries}

As the UNCRPD, it was decided to consider the composition of macro geographical regions and sub-regions devised by the United Nations Statistics Division. This geo-scheme groups continental and geographical sub-regions as follows: Africa (divided into Eastern, Middle, Northern, Southern, and Western Africa), Americas (divided into Latin America -Central and South America- and the Caribbean, and Northern America), Asia (divided into Central, Eastern, Southern, South-Eastern, and Western Asia), Europe (divided into Eastern, Northern, Southern, and Western Europe) and Oceania (divided into Australia and New Zealand, Melanesia, Micronesia, and Polynesia). The countries comprising each of these regions are available on the United Nations website (see http://www.un.org). Moreover, the relationship between these geographical areas and the level of development of the countries was also analysed. To this effect and as there is no established convention for the designation of 'developed' and 'developing' countries or regions, the list provided by the United Nations system was used as a reference: Northern America, Europe, Japan, Australia and New Zealand are considered developed regions; Africa, Central and South America, Caribbean, rest of Asia (i.e. excluding Japan), and rest of Oceania (i.e. excluding Australia and New Zealand) are considered developing regions.

\section{Results of the analysis}

Table 1 shows the total number and percentage of the UNCRPD signatory countries' membership within the IPC and the IOSDs by geographical sub-regions and level of development of the regions. Because of the different number of countries in each region, data should be interpreted in terms of the calculated percentages on the total number of signatories of the UNCRPD. Percentages greater than 100 indicate a number of member countries greater than the number of signatory countries of the UNCRPD.

See table at the end, on page 137

Figure 1 shows a map depicting the overall UNCRPD signatory countries' memberships within the four IOSDs by geographical sub-regions with the aim of facilitating the visualisation and mapping of global data by continents and geographical sub-regions.

See figure at the end, on page 138

\section{GLOBAL OVERVIEW OF THE SIGNATORY STATES OF THE UNCRPD AND ITS RELATION TO THE INTERNATIONAL PARALYMPIC COMMITTEE}

Overall, almost all the signatory countries of the UNCRPD are members of the IPC and have their own NPC. Founded on 22 September 1989 as a non-profit organisation, the IPC replaced the International Co-ordination Committee of World Sports Organisations for the Disabled (ICC) as the global governing body for disabled sport (Brittain 2016b; IPC 2015; Thomas and Smith 2009). The establishment of the IPC 
was an important step forward for the Paralympic Movement that would serve as an umbrella organisation with responsibility for disability sport worldwide. Among others, one of the main responsibilities of the IPC is to ensure that all PwD have equal access to participation in sports events across all levels. As part of this role, it is important to stress the role of a national organisation that would act as the sole representative of athletes' with an impairment from their respective countries under the designation of 'National Paralympic Committee’ (NPC) (Hums et al. 2016). The NPCs became responsible for the entrance, management and athletes' preparation for all the IPC-sanctioned competitions, including Summer and Winter Paralympic Games, which meant that all those countries wishing to be represented in these events of an outstanding global impact would have to fulfil the NPCs membership conditions and comply with their obligations as defined in the IPC Constitution (IPC 2011c, 2015). The foundation of the NPCs was gradual and depended mainly on the existing organisational structure for disabled sports that each country already had (Bailey 2008; Thomas and Smith 2009).

At the time of writing, the IPC currently serves a membership of more than 160 NPCs playing a key role in the major growth of the Paralympic Movement around the world (Brittain 2016b; IPC 2014, 2015; Mauerberg-deCastro, Frances, and Paioli 2016; Thomas and Smith 2009). Apart from this role, the IPC makes an important contribution to the fulfilment of equal competition opportunities for their disabled athletes (LaVaqueManty 2005). The same applies to the competitions of the 13 sports governed by the IPC as an International Federation (Thomas and Smith 2009), within which all countries with an NPC are recognised as their members, hence allowing their nationals to participate in the competitions (IPC 2011d). Thereby, the vast NPCs network has been gradually allowing athletes from countries all around the world, with no discrimination between regions and level of development of the regions, to participate in the IPC-sanctioned Regional and International competitions of multiple sports (Brittain 2016b). However, although this large international presence would reflect an important institutionalorganisational enforcement of human rights regarding states' duties under the UNCRPD to promote sports opportunities at all levels as discussed in this paper, previous research has highlighted the lack of participation from developing countries in international disability sport competitions, especially in heavily indebted poor countries. Several factors may have influenced the lack participation of athletes from developing countries in international disability competitions (e.g. political factors, historical origins and regional growth of international governing bodies and their membership, location of the host city and associated travel costs, climate and geographic barriers, etc.) (Lauff 2011), hence hindering the potentialities of PwD from these countries to become Paralympic athletes (IPC 2011d, 2015). In this regard, the relationship between the level of development of a country and the level of its sporting development has been widely analysed, highlighting the economic development as the "only basic recipe against sporting underdevelopment” (Andreff 2001).

Despite the important role that, in any case, the IPC and the NPCs have played in the protection of the rights of athletes with disabilities to participate in top-level sporting competitions worldwide, in particular for the nationals of the UNCRPD signatory countries, the isolated consideration of the NPCs' insights can hide potential differences 
concerning the encouragement and promotion of the participation of PwD in mainstream sporting activities when comparing impairment specific sports. In this regard, a detailed analysis of the UNCRPD signatories' membership within the IOSDs, which are recognised by the IPC as the international independent organisations acting as the governing bodies of a specific impairment group, might contribute to point out potential differences in terms of geographical location and impairment specific sports between the signatories of the Convention. Overall, developing regions (Africa, the Americas except Northern America, Asia, and Oceania except Australia and New Zealand) exhibited a notably lower number of members within the IOSDs than those in developed regions (Northern America, Europe, and Australia and New Zealand), with figures in many cases below 50 per cent of countries with representatives in these organisations in comparison to the total number of signatories of the UNCRPD within the region. In particular, this holds for the three IOSDs representing athletes with cerebral palsy, intellectual disabilities and wheelchairs and amputees (i.e. CPISRA, INAS and IWAS respectively).

This scenario suggests a minor interest, or at least more difficulties, by the UNCRPD signatory countries in developing regions to promote the foundation and development of national federations or organisations for the representation of athletes within the above mentioned particular impairment groups at the international competitive level. Local national federations and/or sport organisations constitute the backbone of each country's sporting environment, providing opportunities for well organised and structured participation in a particular sport or groups of sports. The role of these national sport governing bodies is critical to increase the participation in recreational and sporting activities, especially in the case of our group as they may face several additional barriers to becoming involved in sport compared with people without a disability (e.g. lack of accessible sport facilities and venues, lack of early experiences in sport, limited opportunities and programmes for participation, training and competition, etc.). The importance of a strong and well-organised sport governance structure, as Chappelet (2014) remarks, is particularly relevant for our target group, as it is the only possible path to successfully break down the aforementioned barriers and enhance participation from the grassroots to the elite level, as well as from the local to the international level.

A variety of barriers accentuated in developing countries by their interconnection with a range of economic, politic, social and cultural barriers that impact on sport participation (Monnington 2005), in the light of the international scenario which has been exposed resulted in a widespread lack of national organisations that could provide sporting opportunities for athletes with disabilities within the three aforementioned specific impairment groups (i.e. cerebral palsy, intellectual disabilities and wheelchairs and amputees) in the developing regions, at least for the analysed UNCRPD signatory countries. Hence not contributing with appropriate institutional measures to ensure that their nationals with these specific impairments have the opportunity to participate in sporting activities to the fullest extent possible at all levels (i.e. regional, continental and international competitions organised by the IOSDs as the representative of a specific impairment group within the IPC structure: CPISRA, INAS and IWAS respectively). The opposite is the case of the International Blind Sports Federation (IBSA), which shows memberships ratios very close to the total number of the UNCRPD signatories in all the 
regions with no notable differences in terms of their level of development. Conversely, the significant number of the states in developing regions with current membership in the IBSA reflects a widespread institutional support for the promotion of sporting opportunities for athletes with vision impairment worldwide.

Most interestingly, the above scenario would lead to a potentially higher enjoyment of the rights by persons with visual impairments to participate in sporting competitions at the international level in comparison to athletes with cerebral palsy, intellectual disability or wheelchair and amputees, in particular in the UNCRPD signatory countries. This fact could be explained in terms of unlikely focus preference of national policies and programmes to implement a disability-specific sport environment for the blind, but in terms of a greater and wider capacity by the International Blind Sports Federation to exercise its functions in order to ensure the growth and strength of the Blind Sports Movement through the development of National Member Federations in all countries. Multiple factors relating to economic, corporate status, strategic partnerships, among others, might explain the increased capacity of the IBSA in comparison to the other three IOSDs (i.e. CPISRA, INAS and IWAS). Future studies may try to decipher the specific causes for this. In any case and whatever the reasons, a significant increase in the overall membership, especially in less represented regions (i.e. developing regions), is countersigned as a priority in the current strategic plans of the three IODSs with less international representation, in which they present their aims and ambitions for the upcoming years (CPISRA 2013; INAS 2013; IWAS 2013). A fact that would contribute greatly to the reinforcement of human rights regarding countries' institutional obligations under the UNCRPD to promote sports opportunities at all levels without discrimination on the basis of the type of impairment as discussed in this article.

\section{CONCLUDING REMARKS}

The fact that a country is represented within the analysed international disabledspecific sporting entities (i.e. IPC member through a NPC and/or member of the IOSDs) does not necessarily mean that it has national athletes playing regularly sport. However, this constitutes the first necessary institutional step to allow their nationals to take part in the competitions organised by these bodies, as these international entities are constituted by the different national federations or organisations of their member countries. Since this was an exploratory study of the global picture, the presence of the UNCRPD signatory countries in the aforementioned organisations would reflect an important institutionalorganisational enforcement of human rights regarding countries' obligations under the UNCRPD to promote and protect PwD' rights as they relate to sport participation to the fullest extent possible at all levels as discussed in the article.

Overall, the international picture shows two different scenarios. On the one hand, the fact that almost all countries that ratified the UNCRPD are IPC members, with no notable differences in terms of geographical location or level of development of the regions, reveals the extensive presence of the Paralympic Movement worldwide and highlights the key role of the NPCs as the national governing bodies for allowing their para-athletes' participation in international sporting competitions. Hence protecting 
PwD' human rights within the signatory countries as they relate to participation in sporting activities, at least from the institutional-organisational sense. On the other hand, the presence of the different UNCRPD signatory countries in the IOSDs shows important differences between regions and level of development of the regions, as well as among the four IOSDs representative of a specific impairment group themselves. Developing regions exhibited a lower number of IOSDs members' countries when compared to the developed regions, in particular for the three IOSDs representing athletes with cerebral palsy, intellectual disabilities and wheelchairs and amputees (CPISRA, INAS and IWAS). Conversely, the IOSD for the blind (IBSA) shows membership ratios very close to the total number of the UNCRPD signatories in all the regions without notable differences in terms of geographical location or level of development of the regions. As discussed above, this scenario leads to higher potential enjoyment of the rights to participate in sporting competitions at all levels by persons with visual impairments in comparison to athletes with cerebral palsy, intellectual disability or wheelchair-users and amputees, in particular in the UNCRPD signatory countries.

Based on the above situation, specific significant efforts should be made by countries in developing regions to gain representation in the IOSDs representing athletes with cerebral palsy, intellectual disabilities and wheelchairs and amputees. To this end, local governments should take the appropriate measures (e.g. funds, resources, facilities, training and policies) to enable the creation of national federations and/or organisations to provide opportunities for well organised and structured participation in sports by people within these specific impairment groups. The example to follow is drawn by the significant number of signatories' members within the IBSA with no notable differences in terms of geographical location or level of development of the regions, reflecting a widespread local institutional support for the promotion of sporting opportunities for athletes with vision impairment that result in the fulfilment of opportunities provision for their disabled athletes to participate in international sporting competitions, hence promoting elite disability sport as a fundamental human right.

As with any research, there are some limitations to this study. In particular, two main limitations should be acknowledged. First and most importantly, as was explained in the introduction, it was argued that the membership of the UNCRPD signatory countries within the different international disabled-specific sporting entities would reflect the extent to which the countries respond to the fulfilment of opportunities provision for their disabled athletes to participate in international sporting competitions, hence protecting their human rights. This research approach may hide the case of countries not yet having international representation in these organisations but already effectively taking the appropriate measures to promote the participation of $\mathrm{PwD}$ in sporting activities, but which in such possible cases would still be far from achieving their athletes' participation to the fullest extent possible at all levels (i.e. international competitions). Second and relatedly, the possible presence of the signatory countries within other disabled-specific International Federations not within the group of the IODSs was not taken into account. However, since the purpose of this research was to provide an exploratory worldwide country situational analysis with the aim of depicting the global scenario in relation to the institutional-organisational status within the signatory countries 
of the UNCRPD in order to promote and develop competition opportunities for their athletes, we modestly believe that it constitutes a fair representation of the current global picture that might be valuable in informing academics, institutions and professionals on the intersections between sport and human rights towards the integration of PwD into society through the participation in sports at all levels, including elite disability sport.

\section{REFERENCES}

Aitchison, C. (2009) Exclusive discourses: Leisure studies and disability. Leisure Studies, 28(4), 375-386. DOI: https://doi.org/10.1080/02614360903125096

Andreff, W. (2001) The correlation between economic underdevelopment and sport. European Sport Management Quarterly, 1(4), 251-279. DOI: https://doi.org/10.1080/16184740108721902

Australian Sport Commission (2010) Participation and non-participation of people with disability in sport and active recreation. Retrieved from https://www.clearinghouseforsport.gov.au/_data/assets/pdf_file/0003/472710/D isability_Sport_Research_Report_FINAL.pdf.

Australian Sports Commission. (2016) AusPlay. Participation data for the Sport Sector. Australian Sport Commission. Retrieved from

http://www.ausport.gov.au/_data/assets/pdf_file/0007/653875/34648_AusPlay_summa ry_report_accessible_FINAL_updated_211216.pdf.

Bailey, S. (2008) Athlete first: A history of the Paralympic movement. New Jersey: WileyBlackwell.

Brittain, I. (2016a) Disability sport. In T. Byers (Ed.) Contemporary issues in sport management. A critical introduction (pp. 315-332). London: Sage.

Brittain, I. (2016b) The Paralympic Games explained. Abingdon: Routledge.

Brittain, I. and Wolff, E. (2015) Disability sport: Changing lives, changing perspectives, Journal of Sport for Development, 3(5), 1-3.

Chappelet, J.L. (2014) The global governance of sport: An overview. In I. Henry and L.M. Ko (Eds.) Routledge handbook of sport policy (pp. 63-74). Abingdon: Routledge.

Cottingham, M., Blais, D., Gearity, B., Bogle, K. and Zapalac, R. (2015) A qualitative examination of Latin American Wheelchair sport practitioners' marketing practices. Journal of Sport for Development, 3(5), 8-19.

CPISRA (2013) Strategic directions. Retrieved from http://cpisra.org/dir/about2/strategic-direction/

Darcy, S. and Taylor, T. (2009) Disability citizenship: An Australian human rights analysis of the cultural industries. Leisure Studies, 28(4), 419-441. DOI: https://doi.org/10.1080/02614360903071753 
Darcy, S., Taylor, T. and Green, J. (2016) ‘But I can do the job’: Examining disability employment practices through human rights complaint cases. Disability \&Society, 31(9), 1242-1274. DOI: https://doi.org/10.1080/09687599.2016.1256807

De Jong, R., Vanreusel, B. and Van Driel, R. (2010) Relationships between mainstream participation rates and elite sport success in disability sport. European Journal of Adapted Physical Activity, 3(1), 18-29.

DePauw, K., and Gavron, S. (2005) Disability sport ( ${ }^{\text {nd }}$ ed.). Champaign, Illinois: Human Kinetics.

Donnelly, P. (2008) Sport and human rights. Sport in Society, 11(4), 381-394.

DOI: https://doi.org/10.1080/17430430802019326

English Federation of Disability Sport (EFDS). (2015a) Making active lives possible: A charter for change. Retrieved from

http://www.efds.co.uk/assets/0001/1898/EFDS_Charter_for_Change_12Feb15.pdf

English Federation of Disability Sport (EFDS) (2015b). Active People 9 full factsheet. Retrieved from

http://www.efds.co.uk/assets/0001/7477/APS9_Full_Factsheet_December_2015.pdf

Equality and Human Rights Commission (EHRC) (2017). Being disabled in England. A journey less equal. Retrieved from

https://www.equalityhumanrights.com/sites/default/files/being-disabled-in-britain.pdf

Erickson, W., Lee, C. and von Scharader, S. (2014) 2013 Disability status report. Retrieved from http://www.disabilitystatistics.org

European Disability Forum (2017) The EU has ratified the Convention. What does this mean?. Retrieved from http://www.edf-feph.org/eu-has-ratified-conventionwhat-does-mean

Eurostat (2015) People in the EU: who are we and how do we live? Luxembourg: Eurostat. Retrieved from

http://ec.europa.eu/eurostat/documents/3217494/7089681/KS-04-15-567-ENN.pdf/8b2459fe-0e4e-4bb7-bca7-7522999c3bfd

Heywood, A. (2000) Key concepts in politics. Basingstoke, Hampshire: Palgrave.

Hylton, K., Bramham, P., Jackson, D. and Nesti, M. (2001) Sports development: Policy, process and practice. London: Routledge.

Hylton, K. and Totten, M. (2001) Developing 'Sport for All?' Addressing inequality in sport. In K. Hylton, P. Bramham, D. Jackson., and M. Nesti (Eds.) Sports development: Policy, process and practice (pp. 37-65). London: Routledge.

Hums, M. A., Schmidt, S. H., Novak, A. and Wolff, E. A. (2016) Universal design: Moving the Americans with Disabilities Act from access to inclusion. Journal of Legal Aspects of Sport, 26 (1), 36-51.

DOI: https://doi.org/10.1123/jlas.2015-0011 
INAS (2013) Shaping our future: INAS Strategic Plan 2013-2017. Retrieved from http://www.inas.org/wp-content/uploads/2011/02/INAS-Business-plan-20132017.Final_.pdf

International Paralympic Committee (IPC) (2011a). Memorandum: Position statement regarding the participation of athletes with an intellectual disability at IPC sanctioned competition. Retrieved from

http://www.paralympic.org/release/Main_Sections_Menu/Classification/2006_12_19_I NAS_Position_Statement.pdf

IPC (2011b) IPC policy on the nationality of competitors. Retrieved from https://www.paralympic.org/the-ipc/handbook

IPC (2011c) Bylaws governance and management. Retrieved from https://www.paralympic.org/the-ipc/handbook

IPC (2011d) Policy for granting the status 'IPC recognized International Federation'. Retrieved from https://www.paralympic.org/the-ipc/handbook

IPC (2014) Celebrating 25 years of the International Paralympic Committee: 1989-2014. Retrieved from

https://www.paralympic.org/sites/default/files/magazine/150416110845501_WEB_Para lympian_03_2014_lowres.pdf

IPC (2015) Strategic Plan 2015 to 2018. Strategic outlook for the International Paralympic Committee. Retrieved from

https://www.paralympic.org/sites/default/files/document/150916131143110_2015_09\% 2BIPC\%2BStrategic\%2BPlan\%2B2015-2018_Digital_v2.pdf

IWAS (2013) IAS Strategic Plan: 2014-2018. Retrieved from

http://www.iwasf.com/iwasf/assets/File/Executive\%20Board/STRATEGIC\%20PLAN \%20-\%202014-2018.pdf

Lauff, J. (2011) Participation rates of developing countries in international disability sport: a summary and the importance of statistics for understanding and planning. Sport in Society, 14, 1280-1284.

DOI: https://doi.org/10.1080/17430437.2011.614784

La Vaque-Manty, M. (2005) Equal opportunity to meaningful competitions: Disability rights and justice in sports. Disability Studies Quarterly, 25(3). Retrieved from http://dsq-sds.org/article/view/573/750

Mauerberg-deCastro, E., Frances, D. and Paioli, C. (2016). The global reality of the Paralympic movement: Challenges and opportunities in disability sports. Motriz, 22(3), 111-123. DOI: https://doi.org/10.1590/S1980-6574201600030001

Misener, L. and Darcy, S. (2014). Managing disability sport: From athletes with disabilities to inclusive organisational perspectives. Sport Management Review, 17, 1-7. DOI: https://doi.org/10.1016/j.smr.2013.12.003

Monnington, T. (2005) Sport for All in the Third World - Reality or not? Retrieved from http://www.playthegame.org/upload/terry_monnington__sport_for_all_in_the_third_world_-_reality_or_not.pdf 
Nicholson, M. and Stewart, B. (2013) Leisure policy: the example of sport, in T. Blackshaw (Ed.). Routledge handbook of leisure studies (pp. 72-81). Abingdon: Routledge.

Paramio-Salcines, J.L., Kitchin, P. and Downs, P. (2018). Promoting universal accessibility for fans with disabilities to European stadia and arenas: A holistic journey sequence approach. In D. Hassan (Ed.) Managing sport business: An introduction (2nd edn), London: Routledge.

Paramio-Salcines, J.L., Prieto, J. and Llopis-Goig, R. (2018) Managing sporting access and participation. In D. Hassan (Ed.) Managing sport business: An introduction (2nd edn), London: Routledge.

Paramio-Salcines, J. L., Grady, J. and Downs, P. (2014) Growing the football game: The increasing economic and social relevance of older fans and those with disabilities in the European football industry. Soccer and Society, 15(6), 864-882. DOI: https://doi.org/10.1080/14660970.2014.920623

Patterson, I. and Pegg, S. (2009) Serious leisure and people with intellectual disabilities: benefits and opportunities. Leisure Studies, 28(4), 387-402.

DOI: https://doi.org/10.1080/02614360903071688

Pitts, B.G. and Shapiro, D. (2017) People with disabilities and sport: An exploration of topic inclusion in sport management. Journal of Hospitality, Leisure, Sport \& Tourism Education, 21, 33-45. DOI: https://doi.org/10.1016/j.jhlste.2017.06.003

Radtke, S. and Doll-Tepper, G. (2011) Talent identification and development (TID) programmes for Paralympic Athletes: A cross-national comparison. Paper presented at the IPC World Cup Seminar Paralympic Sport and its development. Vuokatti (Finland).

Roy, E.C. (2007) Aiming for inclusive sport: The legal and practical implications of the United Nation's Disability Convention for Sport, Recreation and Leisure for People with Disabilities. The Entertainment and Sports Law Journal, 5(1), 4. DOI: https://doi.org/10.16997/eslj.75

Shapiro, D. and Pitts, B.G. (2014) What little do we know: Content analysis of disability sport in sport management literature. Journal of Sport Management, 28, 657-671. DOI: https://doi.org/10.1123/JSM.2013-0258

Shukshin, A. (2005) Disabled often among the 'poorest of the poor'. Bulletin of the World Health Organization, 83(4), 241-320.

Singleton, J. and Darcy, S. (2013) 'Cultural life', disability, inclusion and citizenship: moving beyond leisure in isolation. Annals of Leisure Research, 16(3), 183-192. DOI: https://doi.org/10.1080/11745398.2013.826124

Sotiriadou, P. and Wicker, P. (2014) Examining the participation patterns of an ageing population with disabilities in Australia. Sport Management Review, 17, 35-48. DOI: https://doi.org/10.1016/j.smr.2013.04.004

Spanish Paralympic Committee (Comité Paralímpico Español) (2016) Manual de accesibilidad universal a las instalaciones deportivas [Handbook of universal 
accessibility at sports facilities]. Madrid: Consejo Superior de Deportes and Comité Paralímpico Español.

Sport England (2016) Sport England: Towards an active nation. Strategy 2016-2021. Retrieved from https://www.sportengland.org/media/10629/sport-englandtowards-an-active-nation.pdf.

Sport England (2017) Active Lives survey 2015-16. Year 1 report. Retrieved from https://www.sportengland.org/media/11498/active-lives-survey-yr-1-report.pdf.

Taylor, P. (2011). Torkildsen's sport and leisure management. Abingdon: Routledge. DOI:https://doi.org/10.1080/13606719.2011.559091

Thomas, N. and Smith, A. (2009) Disability, sport and society: An introduction. Abingdon: Routledge.

United Nations (2006) Convention on the Rights of Persons with Disabilities. Geneva: United Nations. Retrieved from http://www.un.org/disabilities/documents/convention/convoptprot-e.pdf

United Nations (2016) Decade after global treaty's adoption, persons with disabilities still at 'grave disadvantage'. Retrieved from http://www.un.org/apps/news/story.asp?NewsID=55705\#.WGPZzlPhAnQ

Veal, A. J. (2015) Human rights, leisure and leisure studies. World Leisure Journal, 77(4), 249-272. DOI: https://doi.org/10.1080/16078055.2015.1081271

World Health Organization and World Bank (WHO and WB). (2011) World report on disability. WHO: Geneva.

World Health Organization (WHO) (2013) Disability and health. WHO: Geneva. 
JAIMe Prieto, JuAn L. PARAmio-SALCines

Table 1. Total number and percentage of the Convention signatory countries' memberships within the IPC and the IOSDs by geographical sub-regions and level of development of the regions.

\begin{tabular}{|c|c|c|c|c|c|c|c|c|c|c|c|c|c|c|}
\hline \multirow{3}{*}{$\begin{array}{l}\text { World } \\
\text { region }\end{array}$} & \multirow{3}{*}{$\begin{array}{l}\text { Geographical } \\
\text { sub-regions }\end{array}$} & \multirow{3}{*}{$\begin{array}{l}\text { Level of } \\
\text { development }\end{array}$} & \multirow{3}{*}{$\begin{array}{c}\text { No. of } \\
\text { countries }\end{array}$} & \multirow{3}{*}{$\begin{array}{c}\text { No. of } \\
\text { CRPD } \\
\text { signatories }\end{array}$} & \multirow{2}{*}{\multicolumn{2}{|c|}{ NPC }} & \multicolumn{8}{|c|}{ International Organisations of Sports for the Disabled } \\
\hline & & & & & & & \multicolumn{2}{|c|}{ CPISRA } & \multicolumn{2}{|c|}{ IBSA } & \multicolumn{2}{|c|}{ INAS } & \multicolumn{2}{|c|}{ IWAS } \\
\hline & & & & & $\mathrm{n}$ & $\%$ & $\mathrm{n}$ & $\%$ & $\mathrm{n}$ & $\%$ & $\mathrm{n}$ & $\%$ & $\mathrm{n}$ & $\%$ \\
\hline \multirow[t]{6}{*}{ Africa } & & & 58 & 40 & 48 & 120,0 & 5 & 12,5 & 26 & 65,0 & 11 & 27,5 & 1 & 2,5 \\
\hline & Eastern Africa & Developing & 20 & 12 & 16 & 133,3 & 0 & 0,0 & 7 & 58,3 & 1 & 8,3 & 0 & 0,0 \\
\hline & Middle Africa & Developing & 9 & 5 & 7 & 140,0 & 0 & 0,0 & 4 & 80,0 & 3 & 60,0 & 0 & 0,0 \\
\hline & Northern Africa & Developing & 7 & 6 & 6 & 100,0 & 3 & 50,0 & 5 & 83,3 & 3 & 50,0 & 0 & 0,0 \\
\hline & Southern Africa & Developing & 5 & 3 & 4 & 133,3 & 1 & 33,3 & 2 & 66,7 & 1 & 33,3 & 1 & 33,3 \\
\hline & Western Africa & Developing & 17 & 14 & 15 & 107,1 & 1 & 7,1 & 8 & 57,1 & 3 & 21,4 & 0 & 0,0 \\
\hline \multirow[t]{5}{*}{ Americas } & & & 55 & 31 & 30 & 96,8 & 7 & 22,6 & 24 & 77,4 & 12 & 38,7 & 4 & 12,9 \\
\hline & Caribbean & Developing & 28 & 10 & 11 & 110,0 & 0 & 0,0 & 5 & 50,0 & 2 & 20,0 & 0 & 0,0 \\
\hline & Central America & Developing & 8 & 8 & 7 & 87,5 & 1 & 12,5 & 7 & 87,5 & 4 & 50,0 & 0 & 0,0 \\
\hline & $\begin{array}{l}\text { South America } \\
\text { Northern }\end{array}$ & Developing & 14 & 11 & 9 & 81,8 & 4 & 36,4 & 10 & 90,9 & 4 & 36,4 & 3 & 27,3 \\
\hline & America & Developed & 5 & 2 & 3 & 150,0 & 2 & 100,0 & 2 & 100,0 & 2 & 100,0 & 1 & 50,0 \\
\hline \multirow[t]{6}{*}{ Asia } & & & 50 & 37 & 38 & 102,7 & 16 & 43,2 & 28 & 75,7 & 14 & 37,8 & 13 & 35,1 \\
\hline & Central Asia & Developing & 5 & 3 & 3 & 100,0 & 0 & 0,0 & 4 & 133,3 & 0 & 0,0 & 1 & 33,3 \\
\hline & Eastern Asia & Developing* & 7 & 4 & 4 & 100,0 & 5 & 125,0 & 5 & 125,0 & 4 & 100,0 & 4 & 100,0 \\
\hline & $\begin{array}{l}\text { Southern Asia } \\
\text { South-Eastern }\end{array}$ & Developing & 9 & 7 & 4 & 57,1 & 2 & 28,6 & 4 & 57,1 & 2 & 28,6 & 1 & 14,3 \\
\hline & Asia & Developing & 11 & 9 & 9 & 100,0 & 3 & 33,3 & 7 & 77,8 & 5 & 55,6 & 2 & 22,2 \\
\hline & Western Asia & Developing & 18 & 14 & 18 & 128,6 & 6 & 42,9 & 8 & 57,1 & 3 & 21,4 & 5 & 35,7 \\
\hline \multirow[t]{5}{*}{ Europe } & & & 53 & 41 & 42 & 102,4 & 32 & 78,0 & 44 & 107,3 & 27 & 65,9 & 32 & 78,0 \\
\hline & Eastern Europe & Developed & 10 & 10 & 10 & 100,0 & 7 & 70,0 & 10 & 100,0 & 6 & 60,0 & 6 & 60,0 \\
\hline & Northern Europe & Developed & 18 & 10 & 10 & 100,0 & 12 & 120,0 & 11 & 110,0 & 8 & 80,0 & 9 & 90,0 \\
\hline & Southern Europe & Developed & 16 & 14 & 13 & 92,9 & 5 & 35,7 & 11 & 78,6 & 7 & 50,0 & 6 & 42,9 \\
\hline & Western Europe & Developed & 9 & 7 & 9 & 128,6 & 8 & 114,3 & 12 & 171,4 & 6 & 85,7 & 11 & 157,1 \\
\hline \multirow[t]{5}{*}{ Oceania } & & & 25 & 10 & 8 & 80,0 & 2 & 20,0 & 7 & 70,0 & 2 & 20,0 & 0 & 0,0 \\
\hline & $\begin{array}{l}\text { Australia and } \\
\text { New Zealand }\end{array}$ & Developed & 3 & 2 & 2 & 100,0 & 2 & 100,0 & 2 & 100,0 & 2 & 100,0 & 0 & 0,0 \\
\hline & Melanesia & Developing & 5 & 4 & 4 & 100,0 & 0 & 0,0 & 3 & 75,0 & 0 & 0,0 & 0 & 0,0 \\
\hline & Micronesia & Developing & 7 & 2 & 0 & 0,0 & 0 & 0,0 & 0 & 0,0 & 0 & 0,0 & 0 & 0,0 \\
\hline & Polynesia & Developing & 10 & 2 & 2 & 100,0 & 0 & 0,0 & 2 & 100,0 & 0 & 0,0 & 0 & 0,0 \\
\hline
\end{tabular}


* Japan (Eastern Asia) is considered as a developed country in the used United Nations system. NPC: National Paralympic Committees. CPISRA: Cerebral Palsy International Sports and Recreation Association. IBSA: International Blind Sports Federation. INAS: International Sports Federation for Persons with an Intellectual Disability. IWAS: International Wheelchair and Amputee Sports Federation.

Figure 1. Worldwide map showing the average percentage of the Convention signatory countries' memberships within the four IOSDs by geographical sub-regions.

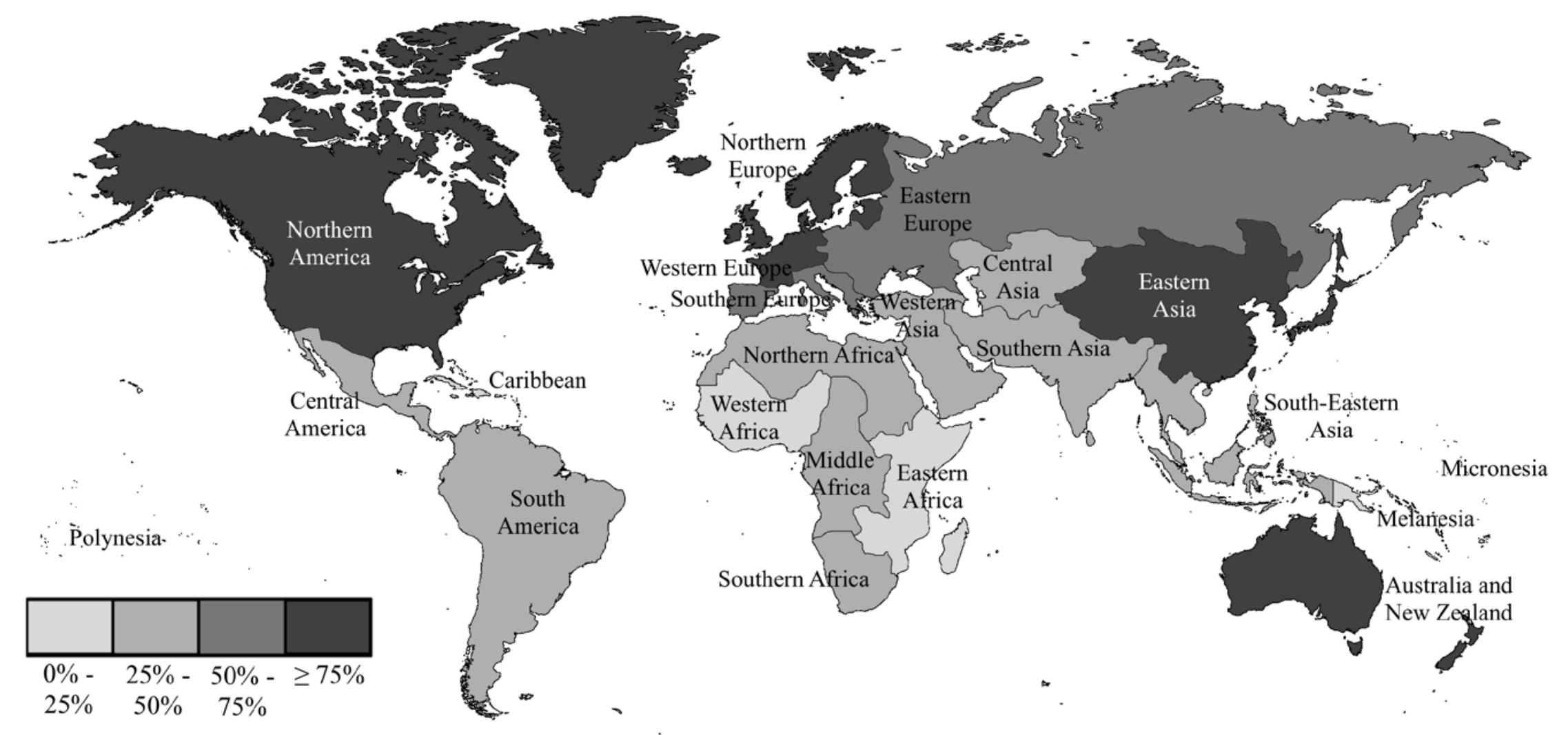

